\title{
Memória e resistência
}

Bernardo Parodi Svartman

OMO compreender o trabalho de criação fotográfica? Se é verdade que nossa percepção nos oferece sempre uma paisagem significativa na qual a vida do pensamento se enraíza, a arte fotográfica, na sua forma própria de organizar o visível, revela a inteligência do olhar, uma atividade sensível de explicitação e criação de sentidos. No jogo de relações que estabelece, no que oculta ou salienta, torna visível um discurso do mundo, dá a ver algo novo ali onde já algo existia. Se estamos agarrados com demasiada intimidade ao mundo, como afirmava Merleau-Ponty, a fotografia rompe a familiaridade, explicita experiências que, tão presentes, tornaram-se imperceptíveis. Num processo próprio de expressão, o fotógrafo toma como material os elos que nos ligam ao mundo para criar visibilidade a partir de um ponto novo, um ponto de vista, um ângulo pessoal.

Quando então falamos sobre as fotos, a interpretação sente o mundo, considera uma abertura ao mundo, e será uma fala que não esgota a complexidade de sentidos do momento capturado. Vista por esse ângulo, a fotografia e o discurso da fotografia terão ao menos uma vantagem em relação ao discurso científico: não renunciam habitar seu objeto, abraçam-no, expõem uma elaboração pessoal; e, ao captar e instaurar sentidos, tornam inesgotável a tarefa que pedem ao seu público.

A proposta de uma investigação fotográfica das formas de habitar o espaço e o tempo do trabalho é exatamente o que encontramos no novo livro de José de Souza Martins, publicado na coleção
"Artistas da USP". Como a pesquisa de experiências psicossociais pede a consideração da memória, do sensível e do imaginário que se costuram na trama das relações e atividades cotidianas, pede, portanto, entrelaçamento de linguagens. Forma de olhar o trabalho que aproxima o cientista social do fotógrafo e poeta.

Os lugares escolhidos para a investigação fotográfica e poética são a vila de Paranapiacaba, a Fábrica de Linhas Pavão (no momento de sua demolição) e a antiga fábrica Cerâmica São Caetano (a fábrica abandonada, algumas semanas antes da demolição). Nas fotografias da vila de Paranapiacaba, seus vagões antigos e abandonados, ou então nas fotografias de ruínas das fábricas, suas máquinas já incompreensíveis, suas estruturas sustentando o vazio, notamos um olhar inconformado. A forma como espaços biográficos, laços do autor, são tomados e trabalhados nas fotos e na poesia revela um poder da memória: expor o conflito entre tempos que se contradizem, o tempo do enraizamento e o tempo das transformações sociais comandadas pela lógica da acumulação.

O livro realiza o projeto de "interrogar aberta e sociologicamente o silêncio, sublinhar a natureza indicial e polissêmica da imagem e do que ela documenta, o momento da sociedade que sobreviveu apenas como traço, sobra e sombra, rabisco da existência humana e social" (p.10). A inspiração do projeto é atribuída a uma passagem de $O$ capital, passagem inusitada na qual Marx emprega a noção de “menos-valia”. Encontramos nas fotos uma interrogação "do menos 


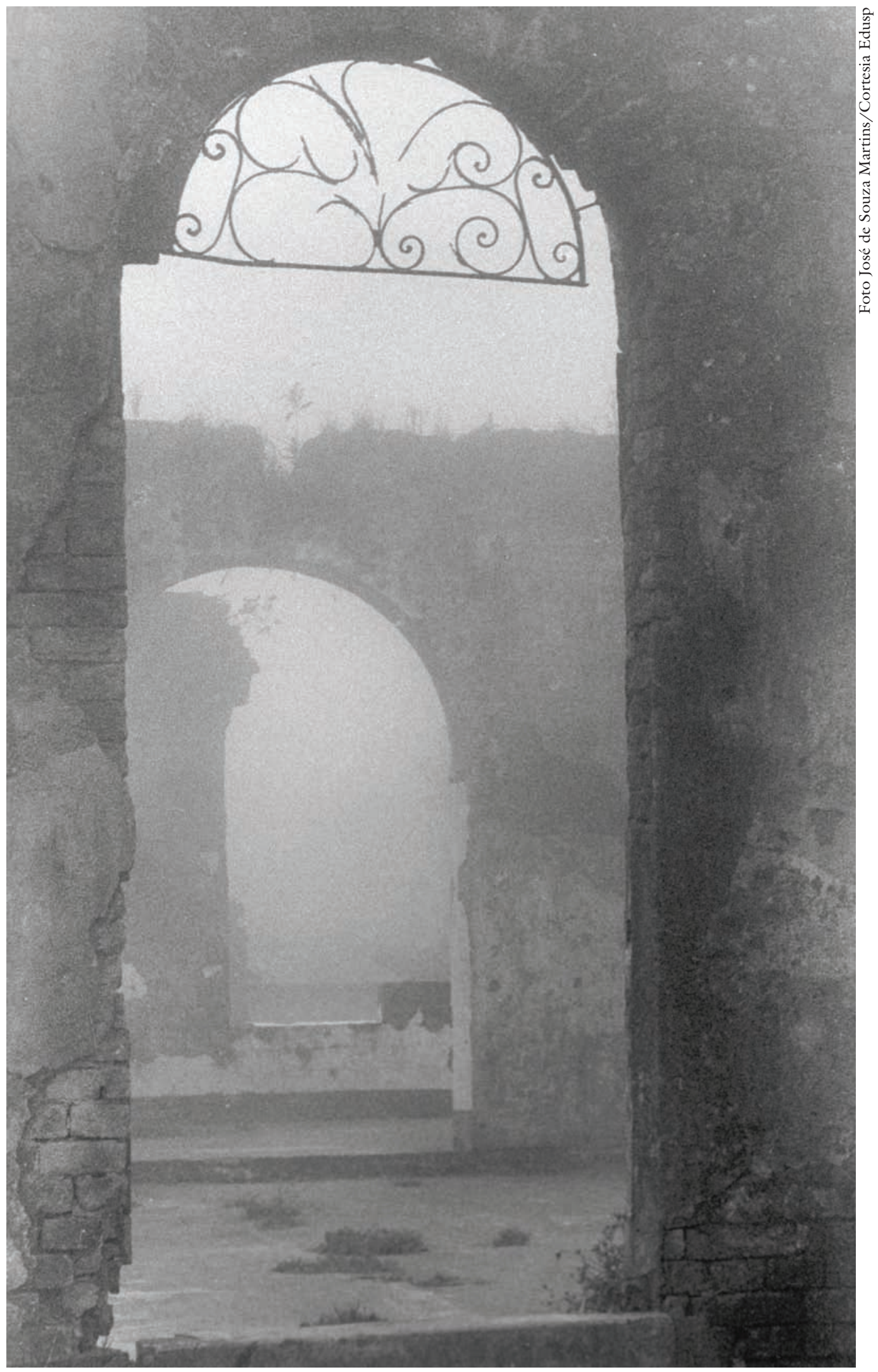


que nasce do mais", investigação de lugares e objetos que, no interior de seu processo de exclusão e deterioração, revelam aspectos da relação humana com a atividade do trabalho em nossa sociedade. Espaços de ausências perturbadoras, exatamente pela maneira como são fotografados: o autor nos convida a decifrar as formas do viver cotidiano daqueles que trabalharam, sonharam, sofreram, testemunharam transformações, habitaram uma circunstância que ruiu. A atmosfera sombria das ruínas fabris, as máquinas vazias, o entulho, a sucata dos trens, todas essas fotos nos fazem considerar experiências também destinadas à invisibilidade. Os espaços mostrados no seu abandono, como se não mais parecessem construídos por mãos humanas, tornam-se quase hieróglifos sociais, signos opacos em que a atenção vulgar não encontra mais nada.

A visão das ruínas, a visão penetrante, entretanto, impõe perguntas. O que resta do trabalho de todos aqueles que ajudaram a construir e a transformar sua cidade? Qual o sentido da permanência ou desaparição dos resultados do trabalho? Como o trabalho e seus produtos se inserem no tempo? O olhar que rememora nos palcos de destruição expõe o abismo entre o tempo de uma vida (seu trabalho, seus sonhos, suas ações) e o tempo da economia ultramoderna: experimentamos a dificuldade de encontrar o sentido de tudo que resultou da atividade coletiva, deparamos com a invisibilidade e o silêncio daqueles que trabalharam mas sumiram. As fotos fazem ver o que não vemos: a vida de sujeitos anônimos no momento em que ajudavam a manter tudo em funcionamento, sem imaginar que todo feito possuía o tempo efêmero da mercadoria. Dessa forma, revela-se a

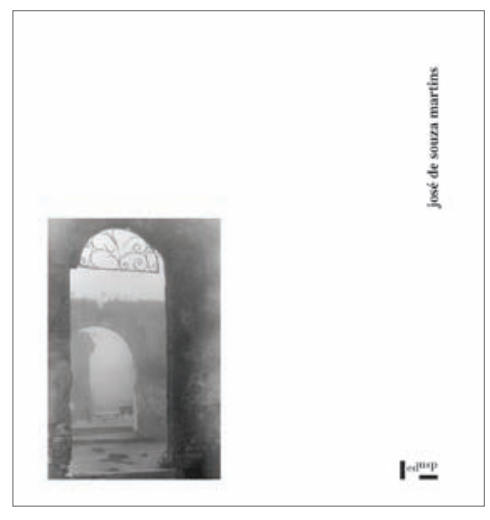

MARTINS, J. de S. José de Souza Martins.

São Paulo: Edusp, 2008. 184p.

(Coleção "Artistas da USP")

coexistência de opostos na produção: o que se constrói de forma estranhada, o sólido que desmancha no ar, a vida que escorre entre engrenagens sem que o sacrifício seja compreensível e justificado. O que construímos fomos nós que construímos? Durou? Para quem? Podemos encontrar nesse jogo entre o visível e o invisível das fotos a tarefa de interpretação proposta ao leitor: o estofo social da memória fotografado nas sombras do que restou.

O leitor é advertido na introdução do livro sobre a intenção que permeará o conjunto da obra: mostrar sobras de trabalho, um conjunto de fraturas, de rupturas no tempo, rupturas entre gerações; o espanto ante o que parecia eterno e, no entanto, era minado internamente, cotidianamente, despercebidamente, no seu próprio ato de reproduzir-se. Nas fotos e na poesia, a relação entre tempo e forma do trabalho coletivo apresenta-se como uma contradição carregada de enorme tensão: o que parecia eterno, afinal, se autodestruía; as maneiras de viver e significar o trabalho em pouco tempo desa- 
pareceriam como se seus agentes fossem tão descartáveis quanto o que produziam. O tempo de enraizamento no trabalho, impedido pelo tempo de obsolescência da mercadoria, impõe no cotidiano dos trabalhadores a tarefa e a necessidade de reparar o sentido perdido.

O livro está dividido em três seções nas quais se entrelaçam fotos e poemas: Paranapiacaba e sua estação de trem, a demolição da Fábrica de Linhas Pavão, a fábrica Cerâmica São Caetano. A composição de imagens e poemas mergulha o leitor nas complexas relações entre a memória e a história, as relações entre o tempo cotidiano e os movimentos ocultos e muitas vezes incompreensíveis da reprodução do capital. A foto de capa, a esse respeito, é sugestiva: apresenta sucessivas portas arruinadas, mergulhadas numa atmosfera esfumaçada e onírica. E nos fez interpretar dessa forma esse trabalho do sociólogo: exame de coisas gradualmente sorvidas por uma embriagante espiral de degradação, a espiral do progresso capitalista. O convite do livro: acompanhar o olhar de uma testemunha, atestando dissolução de lugares e atividades, recolhendo fragmentos e lembranças insistentes nos fragmentos, lembranças mediadoras de nossa reflexão sobre o presente e o futuro.

As fotos da seção "Estação terminal", realizadas em Paranapiacaba, apresentam o emaranhado das novas relações sociais advindas com a chegada do trem e o novo padrão de urbanização que acompanha e excede o engenho ferroviário. Algumas imagens apresentam a nova demarcação do lugar de trabalho e do lugar de controle, demarcação do destino da riqueza e da pobreza. Algumas fotos exploram as relações entre os planos alto e baixo da cidade, o plano acimado da vigilância, de onde vemos sem sermos vistos, e o plano inferior em que só somos vistos: o pan-óptico que inspira a arquitetura da cidade e é prenúncio das novas construções fabris que virão com a industrialização. Na grande maioria das pequenas e médias fábricas do $\mathrm{ABC}$, por exemplo, existe uma imensa janela no andar da administração pela qual se pode fiscalizar toda a produção no chão de fábrica. Os restos desse ambiente urbano classista revelam uma realidade silenciada, a realidade em que a dominação segrega cidadãos e vigia os subordinados, revelam o que precisa ser negado pela mentalidade confiante no contínuo progresso das forças produtivas. E revelam mais: a imagem desse mundo logo decaído parece mostrar que a dominação vive de erguer cidades insólitas, embora não pare de erguê-las, cidades que se transformam continuamente, o insólito de agora sobre o insólito de outrora.

As fotos da seção "Última jornada" fazem ver fases da demolição de uma fábrica de linhas e o amontoado aleatório de peças incompreensíveis que a demolição desagregou. Vivemos uma experiência desconcertante. Inicialmente, cremos ver trabalhadores em atividade comum junto a máquinas. Afinal, reconhecemos o que se passa: são trabalhadores especificamente ocupados com a demolição de uma fábrica. Na demolição, a coisa sobre a qual se trabalha é destinada à destruição: é desmontada ou quebrada; desmancha-se a coerente integridade que the havia sido impressa pela inteligência e pela imaginação humanas; a tarefa demolidora culmina em pedaços sem nexo, cacos em que nada de humano é mais reconhecível. A exterioridade entre trabalhador e coisa marca o curso e o saldo da demolição. $\mathrm{O}$ que precisamos admitir, quando en- 


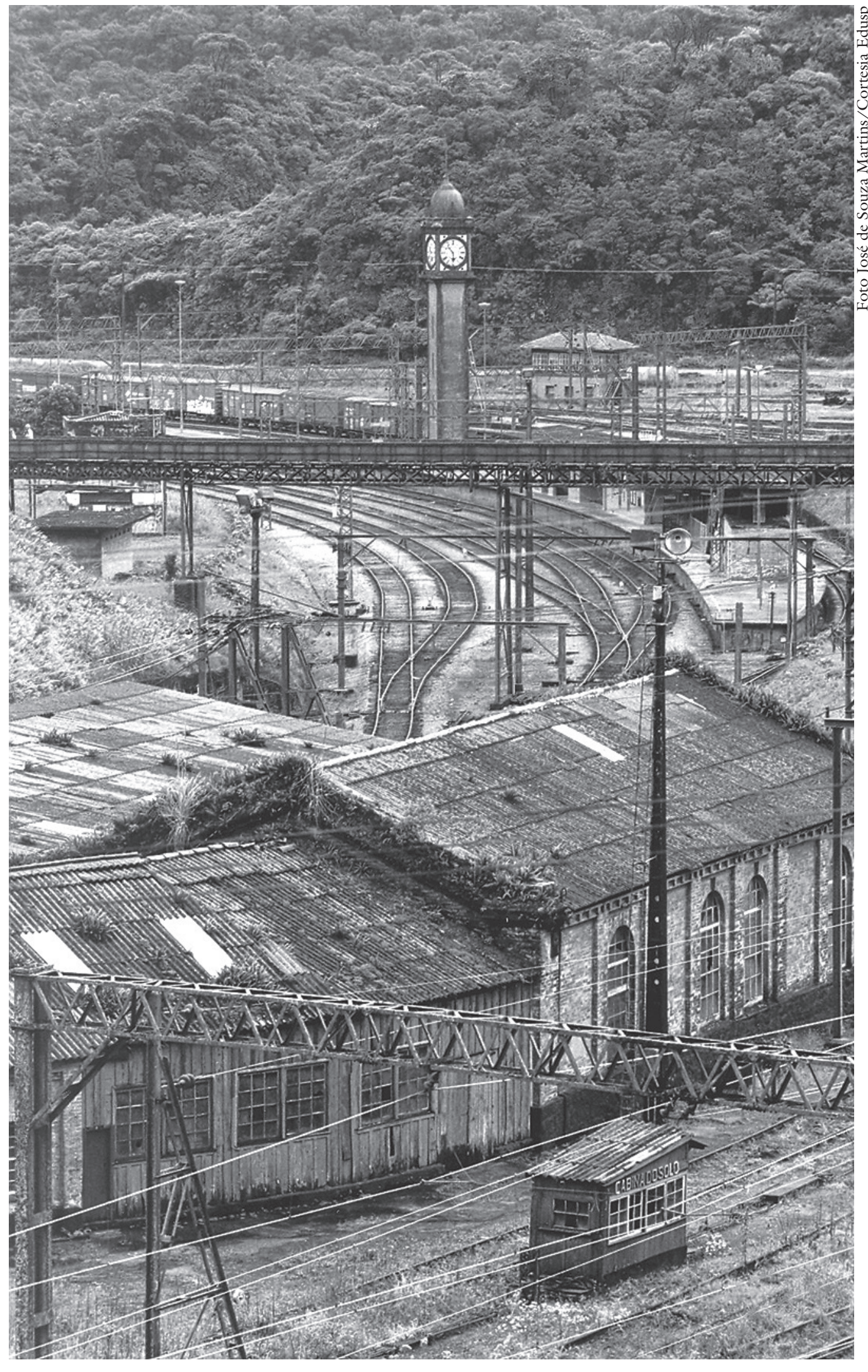




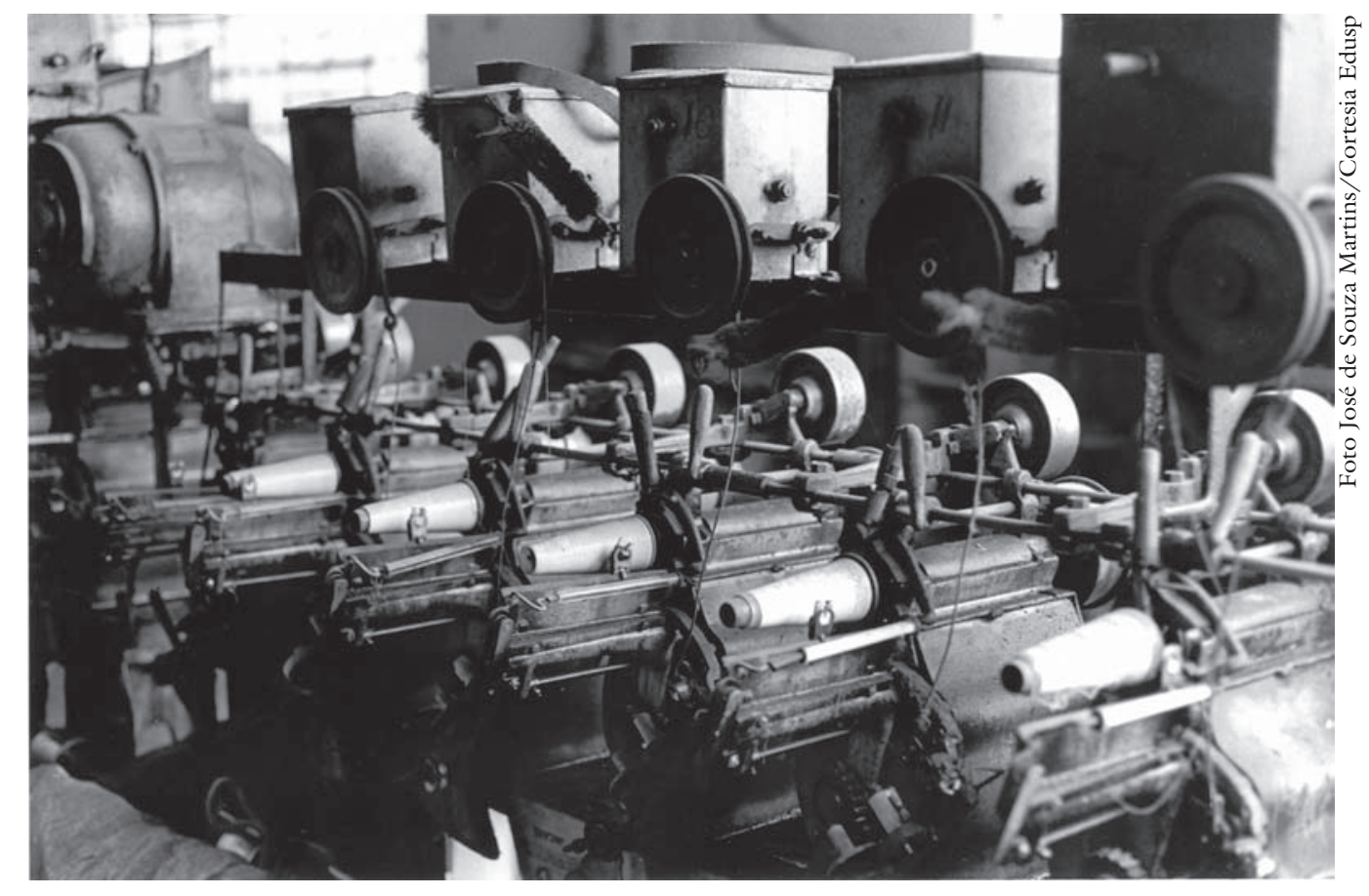

tão confundimos imagens de demolição e imagens do trabalho, é que, entre nós, assumiram um denominador comum: a exterioridade. Nada liga substancialmente o trabalhador ao trabalho alienado. A demolição da fábrica lembra o anterior trabalho nela transcorrido: a demolição é como mais uma jornada, a última. O caráter enigmático do mundo no momento de sua própria produção é explorado na ambiguidade das fotos da destruição como um momento do trabalho social, na destruição como igualmente um debruçar-se de homens sobre as máquinas.

Na seção "A desfabricação da fábrica" estão as imagens da Cerâmica São Caetano, a fábrica desocupada, morta, enferrujada, poucas semanas antes de sua demolição. Nesse lugar o autor trabalhou quando jovem. Ali presenciou o acontecimento densamente explorado em seu célebre texto $A$ aparição do demônio na fábrica. As fotos, os poemas tingidos de lembranças muitíssimo pessoais fazem sentir de forma mais intensa o encontro com o vazio, o silêncio, o espaço desabitado. Encontro entre memória e lacuna, entre a necessidade de enraizamento e o solo árido dos espaços de trabalho. Esse encontro realiza-se no olhar acompanhado da "fala dos ausentes", dos risos de alguns, esperanças e projetos de antigos colegas e companheiros. Nesse ponto revela-se intensamente a substância social da memória, o ponto de vista que informa, a fala do invisível como um fotografar de lembranças assombrando a incompreensível destruição do que outrora pareceu eterno. Como afirma o próprio autor, essas imagens não compõem um simples discurso da negatividade, do que deixou de existir, mas uma tentativa de "ler a escrita visual do negativo".

Podemos observar que o olhar estético que concebe as fotos está informado por inquietações que permeiam toda a obra sociológica de José de Souza Martins: indagar o que está à margem, o que 


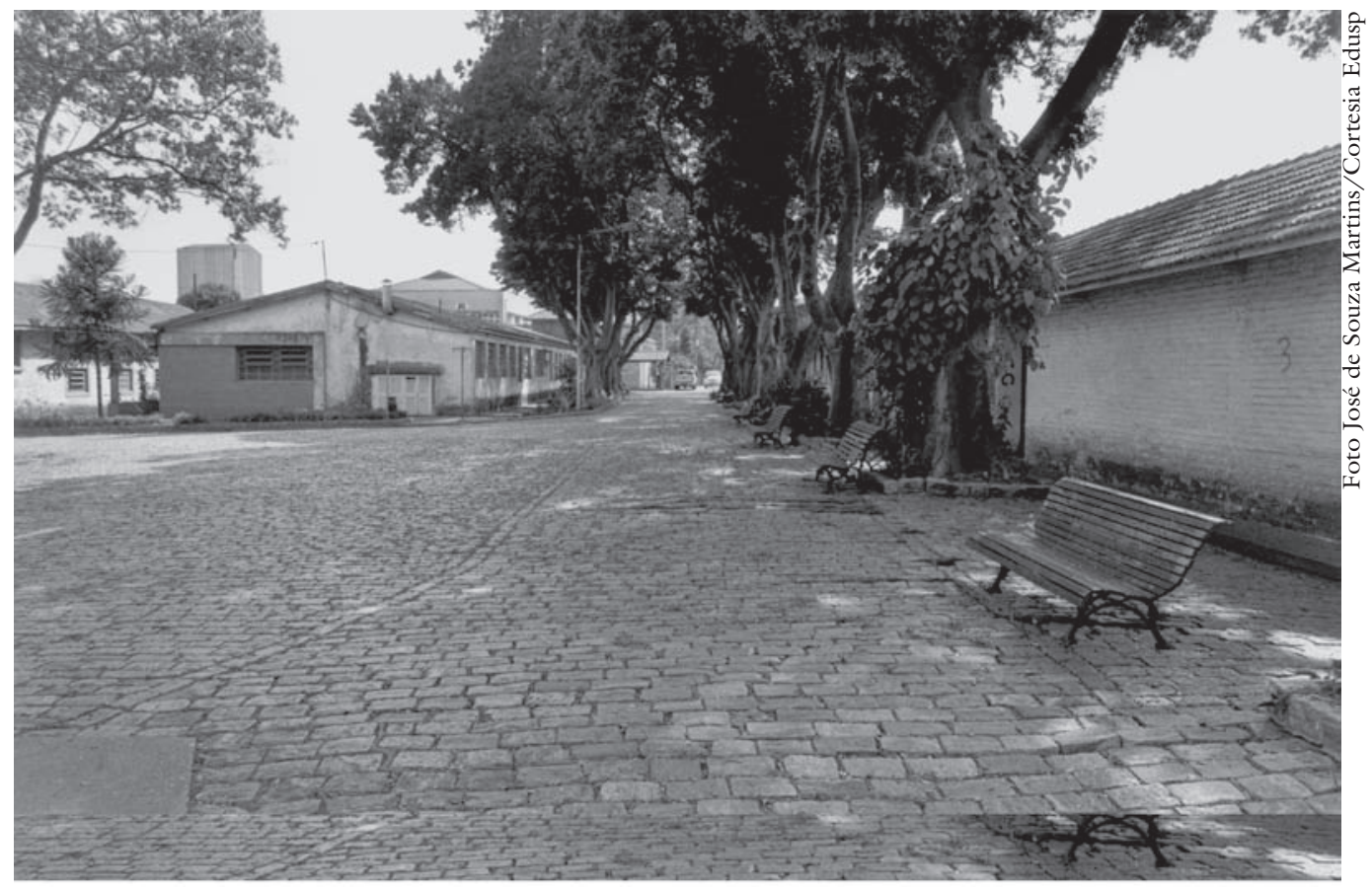

não tem visibilidade na imagem oficial, o que é descartado e nesse processo revela profundamente as contradições de uma forma de produzir que é ao mesmo tempo forma de destruir. Ao contemplarmos esse belíssimo trabalho fotográfico e poético, não podemos deixar de lembrar um trecho de uma entrevista concedida pelo autor em que é possível compreender algo da relação entre sua vida e seu trabalho acadêmico: a tarefa daquele que, chegando do fundo da história, procura encontrar e elaborar sentido no fazer cotidiano que se apresenta como enigma. Isso informa um projeto intelectual e existencial: procurar formas de revelação da realidade que fujam às grandes abstrações que terminam por ocultar as mediações entre o cotidiano e a história. No presente livro, encontramos uma síntese radical de um projeto de investigação social concreta: utilizar a densidade da própria biografia como substrato para uma interrogação em pla- no histórico, plano do destino que nos une e nos separa em torno do trabalho coletivo.

Longe de um projeto realista de documentação, as fotos instauram uma tensão entre os tempos e as gerações, pedem a interpretação do leitor e o remetem continuamente às contradições das transformações sociais. É notável a mediação da memória na elaboração estética da relação do autor com a realidade, processo de criação que instaura uma ordem subversiva de experiências artísticas. Dessa forma, acompanhamos no livro a diluição dos limites que separam as linguagens da arte e da ciência: ciência feita como um artesão que opera nas nervuras do sensível, arte que interroga disciplinadamente e dá o que pensar sobre nossa relação com o espaço e o tempo social. Como já havia sido explicitado por José de Souza Martins, o potencial artístico da fotografia não reside no seu suposto caráter de registro objetivo, mas 
justamente na sua irrealidade, no imaginário impregnado na foto, sustentando interpretações de quem viu e sobre o que foi visto. No caso desse livro, a fotografia atravessada pela memória das perdas, do dilaceramento, escavando o sentido de mudanças espaçotemporais contemporâneas, alargando nossa compreensão do real e nutrindo resistências.

Bernardo Parodi Svartman é professor de Psicologia Social e do Trabalho e membro da equipe de psicologia sócio-histórica da PUC-SP. Também é doutorando em Psicologia Social no Departamento de Psicologia Social e do Trabalho da USP.

@ - bernardosvartman@hotmail.com 